\title{
Pattern of delivery and early initiation of breastfeeding: an urban slum based cross cut study
}

\begin{abstract}
Delivery is a natural phenomenon for reproductive aged women. Normal and cesareanboth are going on and affects early initiation of breast feeding i.e. colostrum feeding. The initiation of breastfeeding within one hour and continuation of only breast milk up to six months ensure maximum benefits. The prevalence of exclusive breastfeeding in Bangladesh is $64 \%$ which is low. Particularly, in slum areas the practice of exclusive breastfeeding among breastfeeding mothers are not being adopted with importance. This cross sectional study was conducted to study pattern of delivery and early initiation of breastfeeding in selected slums of Dhaka city from 1 July'2016 to 10 April'2017 among conveniently selected 354 infant (0-12months)-mother pairs. Two-third and one-third of the deliveries were normal and cesarean. Three-fourth of the births was term birth where one-fourth was delivered as preterm babies. It showed that $44 \%$ infant started breastfeeding within one hour and $56 \%$ started more than one hour. Early initiation of breast feeding was greater among the infants whose pattern of delivery were normal than their cesarean counterpart which was highly significant. Besides percentage of early initiation of breast feeding was greater among the normal term birth babies than that of preterm birth and it was statistically significant. So high rate of early initiation of breast feeding was seen in case of normal delivery and term baby though more than half of the baby started initiation of breast feeding after one hour of birth.
\end{abstract}

Keywords: pattern of delivery, early initiation of breastfeeding, urban slum
Volume 7 Issue 4 - 2017

\author{
Nandeeta Samad,' Md Monoarul Haque, ${ }^{2}$ \\ Sadia Sultana ${ }^{3}$ \\ 'South Asia Institute for Social Transformation, Bangladesh \\ ${ }^{2}$ Bangladesh University of Professionals, Bangladesh \\ ${ }^{3}$ Dhaka National Medical College, Bangladesh
}

Correspondence: Nandeeta Samad, Research Associate, South Asia Institute for Social Transformation, Bangladesh, Email cnbuhs2013@gmail.com

Received: November 17, 2017| Published: December 08, 2017

\section{Introduction}

Establishment of lactation within hours after birth may have important consequences for the health and development of the newborn. ${ }^{1}$ Breastfeeding within an hour of delivery is associated with the establishment of longer and more successful breastfeeding, and of exclusive breastfeeding. The mother also receives positive benefits from breastfeeding within hours of giving birth. Studies have also found association between early cessation of breastfeeding and postnatal depression in mothers. ${ }^{2}$ The early initiation of breastfeeding hastens mother-infant interactions, which are an important component in the early development of a strong and healthy relationship between mother and child.

The exact time of initiation of breastfeeding has been suggested right from birth in the delivery room itself to within one hour after delivery. ${ }^{4}$ Lack of support and lack of knowledge base among health care providers concerning appropriate breastfeeding practice can affect the breastfeeding initiation and duration rates as the majority of the health care providers used their own breastfeeding experiences to replace evidence-based knowledge for mothers. ${ }^{5}$ Early or timely initiation of breastfeeding, specifically within $1 \mathrm{~h}$ of birth, refers to the best practice recommendation by the World Health Organization. ${ }^{6}$ A recent systematic review and meta-analysis revealed that breastfeeding initiation after the first hour of birth doubles the risk of neonatal mortality. ${ }^{7}$. In specific countries, initiating within $1 \mathrm{~h}$ reduced deaths by $19 \%$ in Nepal and $22 \%$ in Ghana. ${ }^{89}$ The evidence, drawn from meta-analysis and over 63 developing countries, shows that early initiation of breastfeeding prevents newborn infections, averts newborn death due to sepsis, pneumonia, diarrhea and hypothermia, and facilitates sustained breastfeeding. ${ }^{10}$ In South Asia, merely $41 \%$ of newborns are breastfed within $1 \mathrm{~h}$ of birth..$^{11}$ This study was an attempt to explore pattern of delivery and early initiation of breastfeeding: an urban slum in cross cut way.

\section{Methodology}

This study was a descriptive cross-sectional study. This study was conducted among 354 breastfeeding mothers of slums (Begunbari Slum Area, Karail Slum Area, Lalbagh Slum Area and Kallyanpur Slum Area) of Dhaka City. The study was conducted from 1 June '2016 to 10 May' 2017. The time preceding and following this period was utilized for questionnaire development, data entry and analysis and final presentation of the study. Those mothers whose children were about $0-12$ months of age and mothers living in the selected slums of Dhaka City were included in the study. The sample was conveniently selected. A questionnaire was developed containing both closed \& open ended questions to obtain relevant information. All questions were designed, pretested, modified and resettled to obtain and record information easily. The purpose of the pretest was to test the content, wording, and expression, the typical sequence of questions and the duration of the interview and the reliability of some items. After pre-test, the individual questionnaire which was related for quantitative data collection were improved and reformed to ensure content coverage, the reliability and validity of the study. The part of the questionnaire that was designed to obtain socioeconomic information was collected by interviewing the respondents. All of the information's were recorded in the respective places of the questionnaire. Data analysis was carried out with the aid of IBM Statistical Package for the Social Sciences (SPSS) version 21.00. 


\section{PATTERN OF DELIVERY}

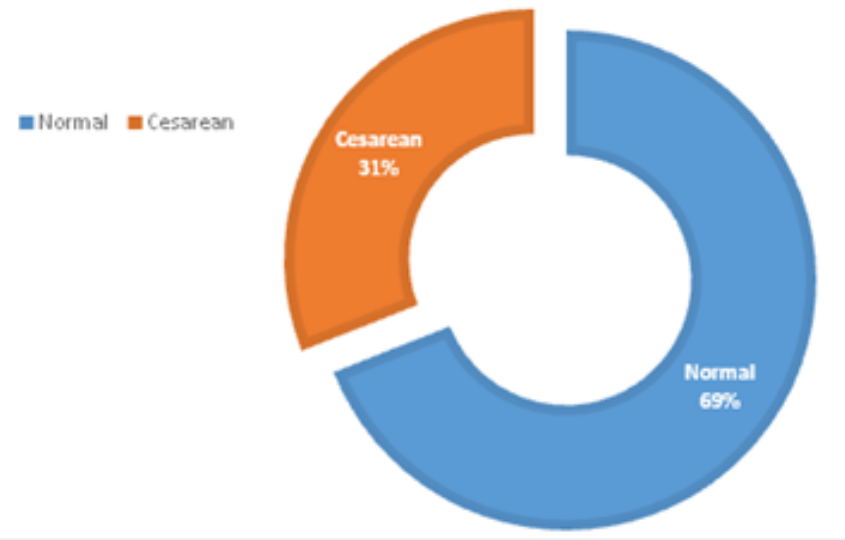

Figure I Pattern of Delivery $(n=354)$.

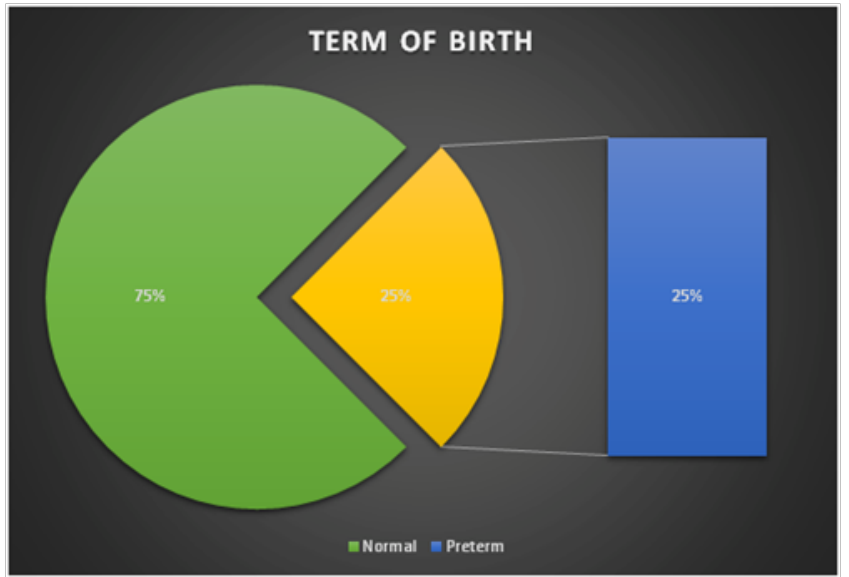

Figure 2 Term of Birth $(n=354)$.

\section{Results}

About $69 \%$ deliveries were normal while $31 \%$ deliveries were cesarean (Figure 1).

About $75.6 \%$ births were term birth but $24.4 \%$ were delivered as preterm babies (Figure 2).

Table 1 represented the rate of early initiation of breastfeeding. It showed that $44 \%$ infant started breastfeeding within one hour and $56 \%$ started more than one hour. Table 2 represented initiation of breastfeeding to infants according to pattern of delivery. It was found that the percentage of early initiation was greater among the infants whose pattern of delivery were normal than their cesarean counterpart. The relationship was highly significant because p-value was found 0.001 after Chi-square test. In terms of cesarean cases mothers' condition remain not so well. Thai's why mothers need special care and they are separated from their babies. For this reason it becomes impossible for mothers to give baby breast milk within one hour after delivery. Table 2 showed that in case of cesarean infants the rate of initiation of breastfeeding within one hour after birth was $21.7 \%$ and more than one hour after birth was $78.3 \%$.It was a big difference. So,
Table 2 proved the hypothesis 'Early initiation (within one hour after birth) of breastfeeding is affected by cesarean delivery.

Table I Early initiation of breastfeeding in infants $(n=354)$

\begin{tabular}{ll}
\hline Initiation of breastfeeding after birth & Percent \\
\hline Within one hour after birth & 44 \\
More than one hour after birth & 56 \\
Total & 100 \\
\hline
\end{tabular}

Table 2 First initiation time of breastfeeding to infants according to pattern of delivery $(n=354)$

\begin{tabular}{llll}
\hline $\begin{array}{l}\text { Pattern of } \\
\text { delivery }\end{array}$ & \multicolumn{2}{l}{$\begin{array}{l}\text { First initiation time of breastfeeding } \\
\text { to infants }\end{array}$} & \multicolumn{2}{c}{ Total } \\
\cline { 2 - 3 } & $\begin{array}{l}\text { Within one hour } \\
\text { after birth }\end{array}$ & $\begin{array}{l}\text { More than one } \\
\text { hour after birth }\end{array}$ & \\
\hline & 110 & 78 & 188 \\
Normal & $57 \%$ & $43.00 \%$ & $100.00 \%$ \\
& 33 & 133 & 166 \\
Cesarean & $21.70 \%$ & $78.30 \%$ & $100.00 \%$ \\
& 143 & 211 & 354 \\
Total & $44.00 \%$ & $56.00 \%$ & $100.00 \%$ \\
\hline
\end{tabular}

P-value (0.00I)

Mother's contact with her baby after delivery according to pattern of delivery was represented in Table 3 . It was found that the percentage of mothers contact with their babies just after delivery was greater in case of normal deliveries than that of cesarean deliveries. The relationship was significant because p-value was found 0.000 after Chi-square test. Mothers contact with baby just after delivery is very much important for early initiation. It was found that the percentage of mothers contact with their infants just after delivery was greater in case of normal deliveries than that of cesarean deliveries. It was found that in case of normal deliveries almost $97.3 \%$ babies were in contact with their mothers just after delivery.

Table 3 showed that in case of in case of cesarean deliveries only $33.3 \%$ mothers were in contact with their babies just after delivery. So, Table 3 proved the hypothesis 'Mothers contact with their babies just after delivery is affected by cesarean delivery (Table 4).

Initiation of breastfeeding to infant according to term of delivery was represented in Table 3. It was found that the percentage of early initiation was greater among the normal birth babies than that of preterm birth. The relationship was highly significant because p-value was found 0.000 after Chi-square test. Table 3 showed that in case of preterm birth infants the rate of initiation of breastfeeding within one hour after birth was $17.6 \%$ and more than one hour after birth was $82.4 \%$. It was a big difference. So, Table 3 proved the hypothesis 'Early initiation (within one hour after birth) of breastfeeding is affected by preterm birth. 
Table 3 Mother's contact with her baby just after delivery according to pattern of delivery $(n=354)$

\begin{tabular}{llll}
\hline \multirow{2}{*}{$\begin{array}{l}\text { Pattern of } \\
\text { Delivery }\end{array}$} & \multicolumn{2}{l}{ Mother's contact with her baby } & \multirow{2}{*}{ Total } \\
\cline { 2 - 3 } & After delivery & No & 264 \\
\cline { 2 - 3 } Normal & 257 & 7 & $100.00 \%$ \\
& $97.30 \%$ & $2.70 \%$ & 90 \\
Cesarean & 30 & 60 & $100.00 \%$ \\
& $33.30 \%$ & $66.70 \%$ & 354 \\
Total & 287 & 67 & $100.00 \%$ \\
\hline
\end{tabular}

P-value $(0.000)$

Table 4 First initiation of breastfeeding to infants according to term of birth $(n=354)$

\begin{tabular}{llll}
\hline \multirow{2}{*}{$\begin{array}{l}\text { Term of } \\
\text { delivery }\end{array}$} & \multicolumn{2}{c}{ Initiation of breastfeeding to infant } & Total \\
\cline { 2 - 3 } & $\begin{array}{l}\text { Within one hour after } \\
\text { birth }\end{array}$ & $\begin{array}{l}\text { More than one } \\
\text { hour after birth }\end{array}$ & \\
\hline \multirow{2}{*}{ Preterm } & 9 & 42 & 51 \\
& $17.60 \%$ & $82.40 \%$ & $100.00 \%$ \\
Normal & 205 & 98 & 303 \\
& $67.60 \%$ & $32.30 \%$ & $100.00 \%$ \\
Total & 214 & 140 & 354 \\
& $60.40 \%$ & $39.50 \%$ & $100.00 \%$ \\
\hline
\end{tabular}

P-value (0.000)

\section{Discussions}

Early initiation of breastfeeding is not only essential for the child, but also for mothers as well. It saves infants' lives, creates bonds between mother and child, helps to reduce post-partum hemorrhage and increases breast milk secretion. Unfortunately the rate of early initiation of breast milk practice to infants is still low in our country. In South Asia, 24\%-26\% of babies born in Bangladesh, India and Pakistan are breastfed within the first hour of birth, whereas the corresponding rate for Sri Lanka is $75 \% .{ }^{12}$ The effect of these breastfeeding patterns is reflected in the neonatal mortality rates for these countries: 40-50 per 1000 live births for Bangladesh, India and Pakistan, while in Sri Lanka the rate is as low as 11 per 1000 live births. ${ }^{13}$ The benefits of breastfeeding for the health and wellbeing of the mother and baby are well documented. A recent trial has shown that early initiation of breastfeeding could reduce neonatal mortality by $22 \%,{ }^{13}$ which would contribute to the achievement of the Millennium Development Goals.

In India, effective implementation of these interventions is yet to be achieved. NFHS-3 data show that the initiation of breastfeeding within one hour is only $24.5 \%$ while exclusive breastfeeding rates in children under six months is only $46.4 \%$ Universalizing early and exclusive breastfeeding in the country will require a national policy and program, along with effective strategies and necessary budgetary provisions. ${ }^{14}$ In many parts of the world, the rates of early initiation of breastfeeding are extremely low: 17\% in Eastern Europe and Central Asian countries, and $33 \%$ in Asia-Pacific. The highest rates (about 50\%) are in Latin America, the Caribbean, East and North Africa. However, for many countries no data are available. ${ }^{15}$ This study represented initiation of breastfeeding to infants according to pattern of delivery. It was found that the percentage of early initiation was greater among the infants whose pattern of delivery were normal than their cesarean counterpart. The relationship was highly significant. In terms of cesarean cases mothers' condition remain not so well. Thai's why mothers need special care and they are separated from their babies. For this reason it becomes impossible for mothers to give baby breast milk within one hour after delivery. In case of cesarean infants the rate of initiation of breastfeeding within one hour after birth was $21.7 \%$ and more than one hour after birth was $78.3 \%$. It was a big difference.

Mother's contact with her baby after delivery according to pattern of delivery was represented in the present study. It was found that the percentage of mothers contact with their babies just after delivery was greater in case of normal deliveries than that of cesarean deliveries. The relationship was significant. Initiation of breastfeeding to infant according to term of delivery was represented here. It was found that the percentage of early initiation was greater among the normal birth babies than that of preterm birth. The relationship was highly significant because p-value was found 0.000 after Chi-square test.

\section{Conclusion}

It is concluded that bigger portion of early initiation of breast feeding was seen in case of normal delivery and term baby though more than half of the baby started initiation of breast feeding after one hour of birth.

\section{Acknowledgements}

None.

\section{Conflict of interest}

The author declares no conflict of interest.

\section{References}

1. Akaike H. Information theory and an extension of the maximum likelihood principle. In: Petrov BN, Csaki F, editors. Second International Symposium on Information Theory. Europe: Hungarian Academy of Sciences; 1973. p. 268-281.

2. AI-Mazroui MJ, Oyejide CO, Bener A, et al. Breastfeeding and supplemental feeding for neonates in AI-Ain. United Arab Emirates. $J$ Trop Pediatr. 1997;43(5):304-306.

3. Badruddin SH, Bazmilinam SN, Ramzanali S, et al. Constraints to adoption of appropriate breast feeding practices in a squatter settlement in Karachi, Pakistan. J Pak Med Assoc. 1997;47(2):63-68.

4. Mamtarani, Srivastava RK, Divakar B. Persuade Mothers in Post Natal Ward for Timely Initiation of Breastfeeding. National Journal of Community Medicine. 2011;2(3):366-370.

5. Fleischer Michaelsen K, Weaver L, Branca F, et al. Feeding and nutrition of infants and young children: Guidelines for the WHO European region, with emphasis on the former Soviet countries. WHO Regional Publications. European Series; 2000:87.

6. Donath S, Amir LH. Rates of breastfeeding in Australia by state and socioeconomic status: evidence from the 1995 National Health Survey. J Paediatr Child Health. 2000;36(2):164-168. 
7. Khan J, Vesel L, Bahl R, et al. Timing of breastfeeding initiation and exclusivity of breastfeeding during the first month of life: Effects on neonatal mortality and morbidity-a systematic review and metaanalysis. Matern Child Nutr. 2015;19(3):468-479.

8. Mullany LC, Katz J, Li YM, et al. Breast-feeding patterns, time to initiation, and mortality risk among newborns in southern Nepal. $J$ Nutr. 2008;138(3):599-603.

9. Tawiah-Agyemang C, Kirkwood BR, Edmond K, Bazzano A, Hill Z Early initiation of breast-feeding in Ghana: barriers and facilitators. $J$ Perinatol. 2008;28:46-52.

10. Edmond KM, Zandoh C, Quigley MA, et al. Delayed breastfeeding initiation increases risk of neonatal mortality. Pediatrics. 2006;117(3):380-386.
11. United Nations Children's Fund (UNICEF). State of the World's Children 2014: every child counts. New York, USA; 2014.

12. Gillie L. Difficulties and discouragement encountered by mother. J Hum Nutr. 2006;30:248.

13. Edmond Karen M, Charles Zandoh, Maria A Quigley, et al. Delayed breastfeeding initiation increases risk of neonatal mortality. Pediatrics. 2006;117(3):380-386.

14. Scott JA, Mostyn T. Women's experience of breastfeeding in a bottlefeeding culture. J Hum Lact. 2003;19(3):270-277.

15. Sulaiman AJM, AI-Riyami A, Farid S. Oman Family Health Survey 2005. J Trop Pediatr. 2011;47(1):1-33. 